\section{The collapsible nature of residual granite soils of the Cape Granite Suite}

\author{
N Fouché, S Y Asante
}

\section{INTRODUCTION}

Where residual granite soils of the Cape Granite Suite, located in the Western Province of South Africa, are identified on-site during a geotechnical investigation, the potential risk of collapse settlement should not be overlooked and will, in all instances, require investigative measures to determine the likelihood and extent of sudden and excessive settlement. The majority of research pertaining to collapsible soils has focused on the problematic basement complex granites situated in the northern part of the country, with much less attention paid to the weathered Cape granites. However, the research carried out on these, often troublesome, Cape granite soils at Stellenbosch University has allowed the researchers to gain valuable insight into their collapse behaviour.

This paper focuses on the nature of the Cape granite soils and presents recent findings with regard to their collapse potential using traditional methods, as well as innovative new techniques such as X-ray computed tomography (CT-scanning) and scanning electron microscopy (SEM).

\section{THE NATURE OF}

\section{COLLAPSIBLE SOILS}

When any open-textured silty or sandy soil with a low dry density (high void ratio) and relatively high shear strength at a low moisture content (due to suction and the presence of bridging colloidal material) is identified during a geotechnical investigation, a soil with collapse potential should be suspected. In the South African context, soils with a collapsible fabric are common in various transported soils (including hillwash, gulley wash and aeolian and littoral deposits), and in a number of residual soils present in regions where quartz-rich rocks such as granite or feldspathic sandstone have undergone chemical weathering to produce intensely leached residual soils (such as residual granite from the Basement
Complex and the Berea Red Sands from Quaternary calcarenites) (Schwartz 1985).

When a partially saturated transported or residual soil with a collapsible fabric wets up under load, the bridging colloids and salts lose strength and stiffness and, as a result, the soil particles are forced into a denser state of packing (termed collapse of the soil structure) (Schwartz 1985).

Cape granite soils have, in the past, frequently been overlooked by engineers and engineering geologists as problem soils with regard to their potential to collapse. In addition, these soils occasionally do not present with the characteristic honeycomblike structure (for example high void ratio and low clay content), and may therefore appear stable. Upon saturation the soil often loses strength and undergoes a substantial decrease in volume. An additional applied load is mostly required to initiate collapse. The potential severity of the problem therefore often goes unnoticed, leading to structural damage, either aesthetically displeasing (for example hairline cracks) and/or structurally significant (for example distortion).

Exposures of Cape Granite Suite rocks are typically restricted to the South Western Cape and daylights in areas such as Stellenbosch, Paarl, Darling, Greyton, Swellendam and the Cape Peninsula (Brink 1981). The widespread occurrence of Cape granites gives an indication of the possible extent of the collapse problem in the South Western Cape.

\section{RESEARCH OBJECTIVES}

The main objectives of the research pertaining to the collapse phenomenon were to:

- Determine the occurrence and extent of collapse settlement in residual and reworked residual Cape granite in the Stellenbosch, Paarl and Darling areas

- Establish the mechanisms of collapse in residual Cape granite
TECHNICAL PAPER

JOURNAL OF THE SOUTH AFRICAN INSTITUTION OF CIVIL ENGINEERING

ISSN 1021-2019

Vol 61 № 2, June 2019, Pages 57-63, Paper 0511

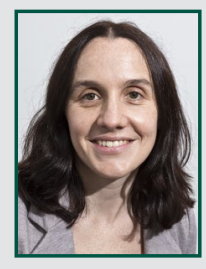

NANINE FOUCHÉ graduated in 2008 with a Bachelor's degree in Earth Science from Stellenbosch University. Thereafter she continued her studies and completed a Post-Graduate Diploma and MScEng in Geotechnical Engineering. Nanine gained valuable experience as an engineering geologist at Aurecon South Africa,

undertaking geotechnical and foundation investigations for a wide range of projects. Her passion for teaching and the academics led her to a career in teaching and research at the Civil Engineering Department of Stellenbosch University. Nanine is currently teaching geotechnical courses, providing support to geotechnical research students and completing her PhD.

Contact details:

Department of Civil Engineering

Stellenbosch University

Private Bag X1

Matieland 7602

South Africa

T: +27218829441

E: naninef@sun.ac.za

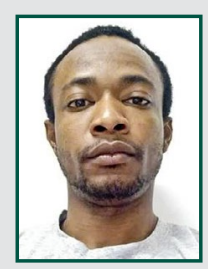

SAMUEL YAW ASANTE is currently a PhD student at Zhejiang University, Hangzhou, China. He holds an MEng in Civil Engineering (Geotechnical option) and a BSC in Geological Engineering from Stellenbosch University, South Africa, and the University of Mines and Technology, Ghana, respectively. His interests lie in soil

behaviour, microstructure characterisation of soil and methane hydrate-bearing sediments, as well as geotechnical laboratory techniques. Since graduation he has worked for a number of companies in Ghana.

Contact details:

D Block Department of Civil Engineering

RM 725 Stellenbosch University

Zhejiang University Private Bag X1

Zijingang Campus Matieland 7602

Hangzhou South Africa

China

T: +233541030717

E: samuelasanteyaw@gmail.com 
- Develop a test procedure to investigate the microstructure of soils to aid in identifying potentially collapsible soils

- Provide insight with regard to the properties and behaviour of the collapsible

Cape granite soils, i.e. possible explanations about the collapse behaviour.

Detailed field investigations comprising

disturbed and undisturbed soil sampling and profiling were carried out by the researchers within the demarcated study areas. A soil testing phase followed, encompassing standard testing methods such as collapse potential tests and newer techniques such as SEM and CT-scanning. Both residual granite (defined as the weathering product of granite parent rock occurring directly above the parent rock) and reworked residual granite (defined as residual granite reworked in-situ by termites) from the investigated areas were included in the study.

\section{DEMARCATED STUDY AREAS}

Selected study areas within the towns of Stellenbosch, Paarl and Darling, all located within the mapped extent of the Cape Granite Suite, formed part of the research area. An additional site in Paarl, underlain by residual Malmesbury shale (which is known to be non-collapsible), was investigated to aid as a control. The following sites make up the greater research area:

- Four sites along the R44 between Stellenbosch and Somerset West: These sites are underlain (partly or entirely) by residual granite and reworked residual granite derived from coarse-grained porphyritic granite of the Kuils River - Helderberg pluton. Various sampling locations were selected within each chosen site, resulting in a total of 17 sampling localities and 18 large undisturbed block samples for laboratory testing.

- Nine sites, of which five are situated at the foot or on the side slopes of the Paarl Pluton within the Paarlberg Reserve, and four sites at the foot of the southern and eastern side slopes of the same Pluton: The sampling areas are underlain by residual granite derived from the Bretagne Granite, Laborie Granite or Montvue Granite. One sample was collected from each of these locations, resulting in a total of nine undisturbed block samples.

- Five sites on farmland in the northern outskirts of Darling: These sites are situated within the boundaries of the
Darling Batholith and are underlain by residual biotite granite. One large undisturbed block sample was collected from each of the sites.

Six undisturbed soil samples comprising residual Malmesbury shale were also sampled from a quarry site in Paarl. These residual Malmesbury soils do not develop a collapsible, honeycomb-like structure and were sampled to compare and to better understand the influence of the soil microstructure on collapsibility of the residual soils.

\section{EXPERIMENTAL WORK METHODOLOGY}

The experimental work carried out by the researchers entailed extensive laboratory testing, including both standard procedures such as consolidometer testing and index type tests (e.g. particle size analysis) and newer, non-destructive techniques, such as CT-scanning and electron microscopy.

The research objectives mentioned before and the corresponding testing methods used in achieving each objective are summarised in Table 1.

The collapse potential of a soil is governed by its microstructure, that is, the porosity, particle and pore size distribution, particle morphology and mineralogy. The use of non-destructive techniques such as CT-scanning and scanning electron microscopy (SEM) to examine the microstructure of soils is currently showing promising progress, with further development in such research techniques. CT-scanning enables the visualisation of the internal structure of objects (such as soils) by converting measured X-ray computed tomography signals to two-dimensional (2D) or three-dimensional (3D) images, whereas SEM operates on optical principles, generating images by scanning the soil surface with a focused beam of electrons. By examining the microstructure of potentially collapsible soils with these techniques, the influence of the various components of the soil microstructure on the behaviour of collapsible soils can be studied. By creating a better understanding of these mechanisms, collapsible soils can potentially be identified by examination of the soil microstructure. CT-scanning and SEM, which formed the basis of the experimental research aimed at developing a test procedure to identify potentially collapsible soils, are briefly discussed below.

CT-scanning involves the visualisation of the internal structure of soils without disturbing the soil structure. The porosity, particle size distribution and pore size distribution of soils can be determined by analysing two- and three-dimensional X-ray images obtained via data acquisition and image reconstruction. To obtain the 3D $\mathrm{X}$-ray images, the General Electric Phoenix VTomeX L240 X-ray micro-computed tomography scanner (microCT) and NanoCT were used for the experimental work in conjunction with VGStudio Max and Avizo Fire Image analysis software. As part of the experimental work multiple scans were performed on reworked residual and residual granite from Stellenbosch, as well as the residual Malmesbury shale from Paarl (functioning as a control). To investigate the soils' microstructure after collapse, a number of reworked residual and residual granitic soil samples were also scanned after completion of the single oedometer testing. An advantage of CT-scanning is the non-destructive nature of the technique, allowing samples to be scanned and subsequently analysed several times.

\section{Table 1 Experimental work to achieve research outcomes}

\section{Research objectives}

To determine the occurrence and extent of collapse settlement in the residual Cape granite in the Stellenbosch, Paarl and Darling areas

To develop a test procedure to investigate the microstructure of soils to aid in identifying potentially collapsible soils

To confirm the mechanism(s) of collapse settlement in residual Cape granite soils

To provide insights with regard to the properties and behaviour of the collapsible Cape granite soils, i.e. possible explanations concerning the collapse behaviour
Testing methods to achieve objective Consolidometer tests including collapse potential, single oedometer and double oedometer tests (in accordance with ASTM D2435 (ASTM 2011), and Jennings and Knight (1975))

CT-scanning and scanning electron microscopy

Standard laboratory procedures (TMH1 1986) to determine particle size distribution, Atterberg limits and dry density, and X-ray diffraction, CT-scanning and scanning electron microscopy 
As a result of its higher resolution and magnification power, SEM has been used to investigate soil microstructure (Remley \& Bradford 1989). It is considered an effective and reliable technique to determine soil mineralogy and particle morphology, which play a significant role in processes such as collapsibility. The SEM generates images by scanning a focused electron beam over the soil surface to create an image.

The ZEISS EVO MA15 scanning electron microscope at the Centre for Analytical Facility at Stellenbosch University was used to determine the mineral composition and morphology of the reworked residual and residual granite from Stellenbosch, Paarl and Darling, and the residual Malmesbury shale from Paarl. A total of 170 images were obtained during the experimental work. Appropriate methods and software packages were used to determine the mineral composition and morphology from these images. The disadvantages of SEM are the time-consuming nature of preparing samples for the microscopy study, lens aberration and long analytical time.

Soil mineral composition can also be determined by means of X-ray diffraction (XRD) and X-ray fluorescence spectrometry (XRF). The clay content and soil fabric of the residual granite sampled from Paarl and Darling were examined by means of $\mathrm{X}$-ray diffraction. However, considering the disadvantages associated with XRD and XRF - such as the limiting depth of X-ray penetration and the influence of water content on the performance and reliability of the results - scanning electron microscopy is the preferred method to determine soil mineralogy (Asante 2015).

\section{EXPERIMENTAL FINDINGS}

\section{Standard laboratory methods}

Double-oedometer, single-oedometer and collapse potential tests confirmed the presence of collapsible soils at the majority of sampling locations underlain by reworked residual and residual granite in the Stellenbosch, Paarl and Darling areas. The reworked residual and residual soils sampled from the demarcated study areas in Stellenbosch are typically moderately collapsible and collapsible, with collapse potential values mostly between $1.7 \%$ and 10\% (maximum 18.4\%). Table 2 provides the descriptive terms associated with the values of collapse potential. The collapse potential test results obtained for a number of reworked residual specimens sampled from a particular site near Stellenbosch are
Table 2 Guiding values of collapse potential (Jennings \& Knight 1975)

Collapse potential Severity of problem

\begin{tabular}{|c|l|}
\hline $0 \%-1 \%$ & No problem \\
\hline $1 \%-5 \%$ & Moderate trouble \\
\hline $5 \%-10 \%$ & Trouble \\
\hline $10 \%-20 \%$ & Severe trouble \\
\hline$>20 \%$ & Very severe trouble \\
\hline
\end{tabular}

shown in Figure 1. From the figure it is evident that, once a critical value of moisture content is exceeded, the fine silt bridges are no longer able to resist deformation, resulting in a sudden and large decrease in soil volume. A slight bow in the compression curves is noted at a vertical stress of about $50 \mathrm{kPa}$, and a slight, but uncharacteristic increase in void ratio between 100 and $200 \mathrm{kPa}$. The cause of these unusual volume changes is uncertain, but it can possibly be ascribed to temperature variations in the soils laboratory bringing about changes in soil moisture.

The residual granites sampled from various sites in Paarl and Darling displayed collapse potential values ranging from $<1 \%$ (not collapsible) to 5.7\% (collapsible), and between $<1 \%$ and $3 \%$ (moderately

Table 3 Summary of experimental findings from standard laboratory tests on reworked residual and residual Cape granite soils (compiled from Gildenhuys 2010; Muteb 2013; Asante 2015)

\begin{tabular}{|c|c|c|c|c|c|c|}
\hline $\begin{array}{l}\text { Sampling } \\
\text { area }\end{array}$ & $\begin{array}{c}\text { Collapse potential } \\
\text { (\%) (number } \\
\text { of samples per } \\
\text { category) }\end{array}$ & Soil type & $\begin{array}{c}\text { Moisture } \\
\text { content range } \\
\text { (average) (\%) }\end{array}$ & $\begin{array}{l}\text { Dry density range } \\
\text { (average) }\left(\mathbf{k g} / \mathrm{m}^{3} \text { ) }\right.\end{array}$ & $\begin{array}{l}\text { Void ratio range } \\
\text { (average) }\end{array}$ & $\begin{array}{c}\text { Clay content } \\
\text { range (average) } \\
(\%)\end{array}$ \\
\hline \multirow{4}{*}{ Stellenbosch } & $<1(4)$ & $\begin{array}{l}\text { sandy clay } \\
\text { clayey silty sand } \\
\text { clayey sand }\end{array}$ & $13.4-27.3(22.3)$ & $1414-1902$ (1 581) & $0.32-0.87(0.71)$ & $21-41(29)$ \\
\hline & $1-5(7)$ & $\begin{array}{l}\text { clayey silty sand } \\
\text { clayey sand } \\
\text { silty sand } \\
\text { sandy clay }\end{array}$ & $5.5-25.5(15.9)$ & $1441-2022(1654)$ & $0.34-0.92(0.63)$ & $9-43(29)$ \\
\hline & $5-10(7)$ & $\begin{array}{l}\text { clayey sand } \\
\text { silty sand }\end{array}$ & $\begin{array}{l}\text { 14.2-18.7 (16.6) } \\
\text { not determined for } \\
\quad \text { all samples }\end{array}$ & $\begin{array}{c}1507 \text { - } 1834 \text { (1 628) } \\
\text { not determined for } \\
\text { all samples }\end{array}$ & $0.51-1.69(1.18)$ & $3-27(16)$ \\
\hline & $10-20(3)$ & silty sand & not determined & not determined & $0.96-0.99(0.98)$ & 1 \\
\hline \multirow{3}{*}{ Paarl } & $<1(4)$ & $\begin{array}{l}\text { silty sand } \\
\text { silt } \\
\text { clayey sand }\end{array}$ & 11.8-25.7 (17.9) & $1310-1574(1455)$ & $0.71-1.0(0.85)$ & $16-33(21.7)$ \\
\hline & $1-5(5)$ & $\begin{array}{l}\text { clayey sand } \\
\text { silty sand }\end{array}$ & $10.8-20.1(15)$ & $1343-1458$ (1 411) & $0.85-1.0(0.91)$ & $14-28(19.5)$ \\
\hline & $5-10(1)$ & clayey sand & 10.9 & 1486 & 0.81 & 28 \\
\hline \multirow[b]{2}{*}{ Darling } & $<1$ (3) & $\begin{array}{l}\text { clayey sandy gravel } \\
\text { clayey sand }\end{array}$ & $11.9-13.6(12.7)$ & $1665-1731$ (1 698) & $0.56-0.62(0.59)$ & $29-33(31)$ \\
\hline & $1-5(5)$ & $\begin{array}{l}\text { clayey sand } \\
\text { silty sand } \\
\text { sandy gravel }\end{array}$ & $10.5-17.1(14.6)$ & $1380-1603(1460)$ & $0.68-0.95(0.85)$ & 3-32 (14.6) \\
\hline
\end{tabular}






Figure 1 Stellenbosch collapse potential test results (Asante 2015)

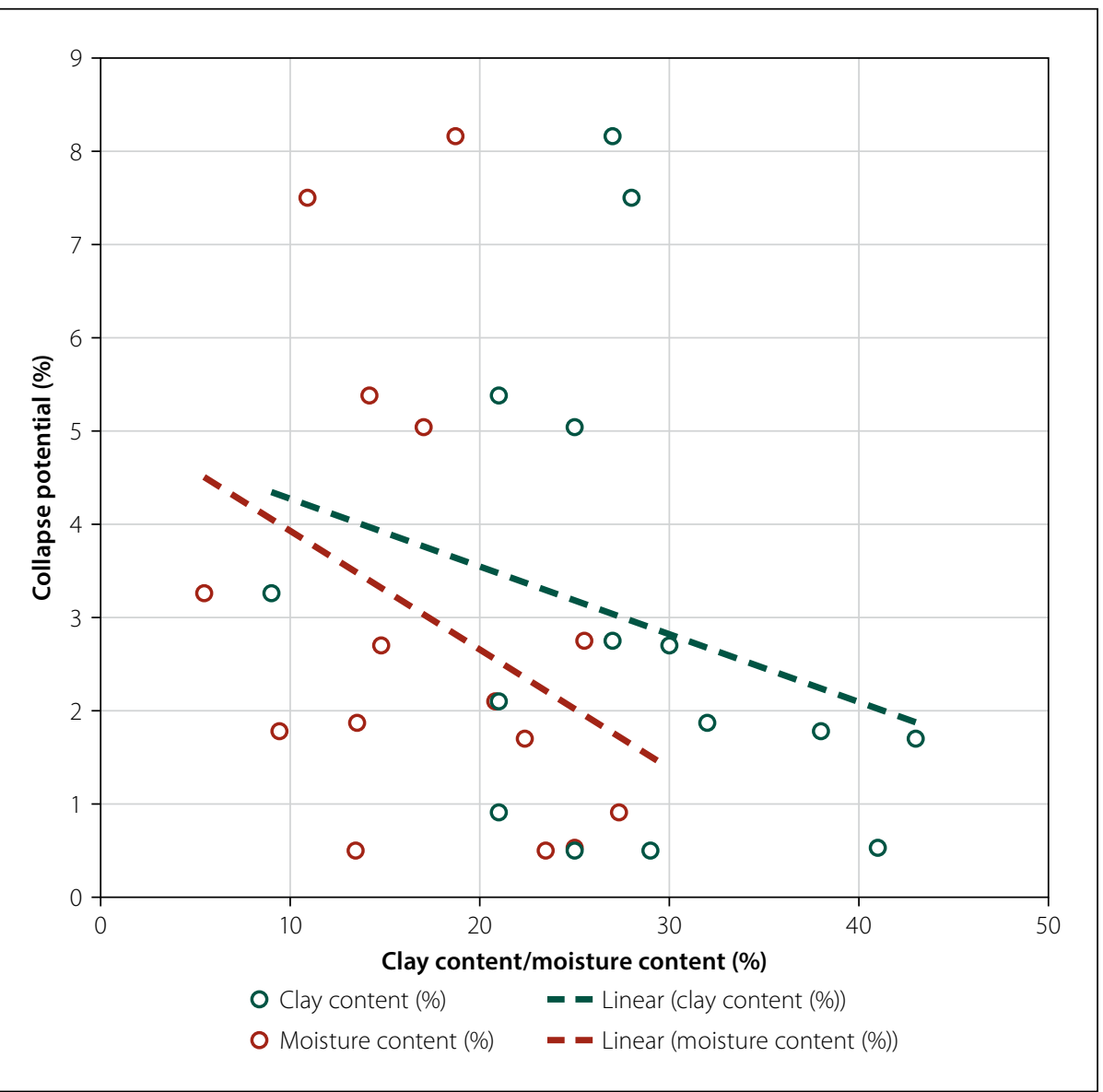

Figure 2 Collapse potential versus clay and moisture content for Cape granite soils collapsible), respectively. Collapse potential tests confirm that the residual

Malmesbury shales sampled from Paarl are not collapsible.

A summary of the characteristics of all reworked residual and residual granite soils sampled from the study areas is presented in Table 3. The parameters were obtained by means of standard laboratory procedures. The collapse potential values given in Table 3 originate from three separate research studies, and are thus an amalgamation of collapse potential, single-oedometer and double-oedometer test results. In addition, both residual and reworked residual specimens were included in the study; however, no distinction is made between the outcomes associated with these two soil types.

From Table 3 the following conclusions can be drawn:

- With an increasing collapse potential (\%), the average clay content and in-situ moisture content (MC) obtained for each collapse potential category tend to decrease (see Figure 2). Notwithstanding this, outliers were observed, particularly at high and low values of collapse potential.

- No clear correlation between dry density and collapse potential could be found; thus accentuating the fallacy in assuming that all soils with a low dry density will have a tendency to collapse, and vice versa. The large range in dry density and void ratio values observed in some instances in the table shows that soil stability is not consistently represented by dry density.

- The average void ratios determined for each collapse category typically increase with increasing collapsibility (see Figure 3). The high collapse potential values (17.11\% and $18.4 \%$ ) associated with the two specimens with void ratios of 0.96 and 0.99 , can possibly be explained by the interconnectedness of the soil voids and/or the particle morphology. These aspects will be discussed as part of the microstructure analysis.

- The tabulated results demonstrate that collapsible residual granite does not necessarily possess typical characteristics associated with collapse, such as a low dry density and clay content.

\section{Microstructure analysis}

The distribution of particle sizes in ten samples of reworked residual granite was determined from CT-scanned images using 


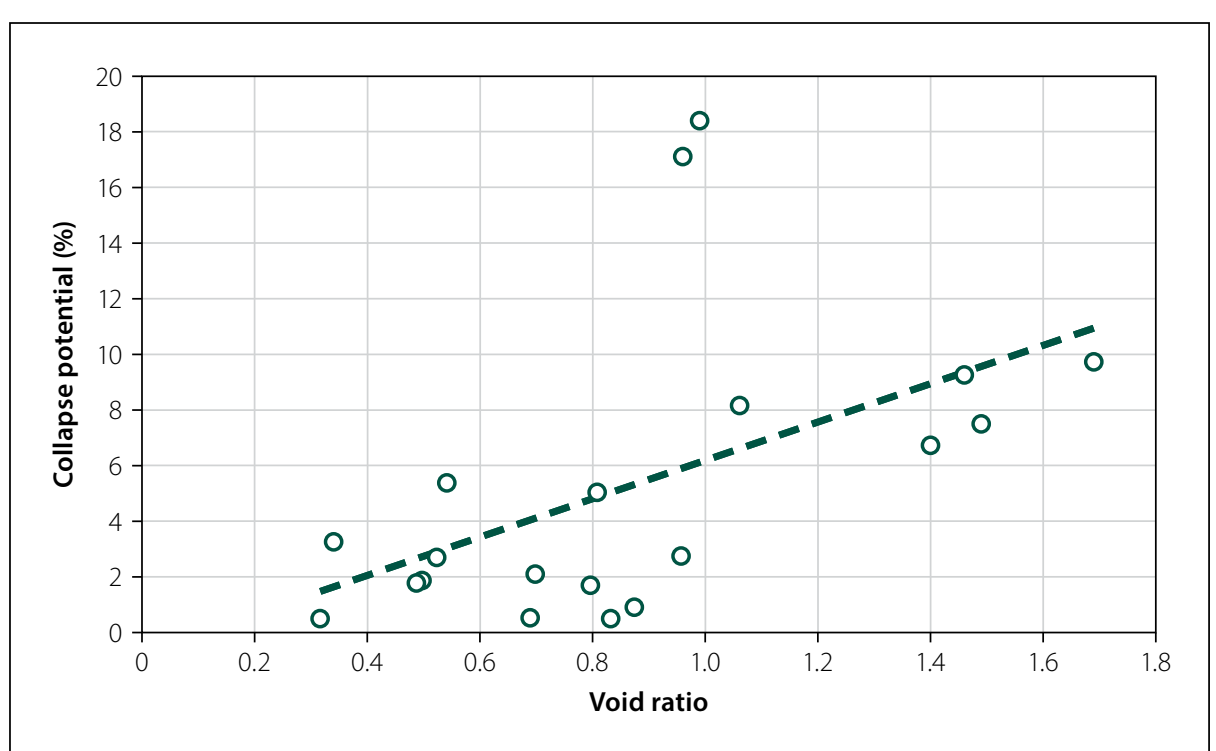

Figure 3 Variation in void ratio with degree of collapse in Cape granite soils

an image processing technique termed granulometry. A typical particle size distribution (PSD) curve is shown in Figure 4. The PSD curve for the same material, but determined by means of mechanical sieving and hydrometer analysis, is also shown on the figure. The mechanical analysis was carried out on the same ten samples in accordance with TMH1 Methods A1, A5 and A6 (TMH1 1986). The minor discrepancy noted for the finer soil particles can be attributed to the tendency of these particles to clump together, subsequently being seen as a single homogenous particle in the digital CT-scan image produced.
This phenomenon, termed bleeding, results in the finer, measured CT-scan particles (silt and clay size) appearing larger than their counterparts measured by means of mechanical sieving and hydrometer analysis. Conversely, an advantage of the CT-scan method is the ability to determine the volume and surface area of the individual particles from which the actual diameter can be calculated. This allows a more accurate size distribution of coarse particles. The more prominent difference in the distribution of coarse particle sizes can thus be ascribed to the inaccuracies of the mechanical sieving method. The
CT-scan method is therefore considered marginally superior with regard to the determination of soil particle sizes, providing slightly more accurate and reliable grading results. Notwithstanding this, the gradations obtained from the traditional and CT-scanning methods are sufficiently similar, providing comparable textural descriptions to aid in identifying a collapsible fabric.

From the CT-scanned images, the porosity of the reworked residual granite and residual Malmesbury shale was studied. This entailed determination of the average volumetric change within the different pore size classes given by Brewer (1964) during collapse of the soil structure. Figure 5 shows the voids present in a scanned image of reworked residual granite before (a) and after collapse (b) of the soil structure. A significant reduction in the volume of coarse macropores (indicated in pink) upon saturation is shown, with the formation of fine and medium macropores (indicated in blue) as the particles rearrange. The results showed a direct correlation between the average volume of connected pores (specifically coarse macropores of $75->5000 \mu \mathrm{m}$ ) and the volumetric change within these pores, and the magnitude of collapse. It was found that the average volume of connected coarse macropores and volumetric change within the non-collapsible residual Malmesbury shale were significantly lower than within

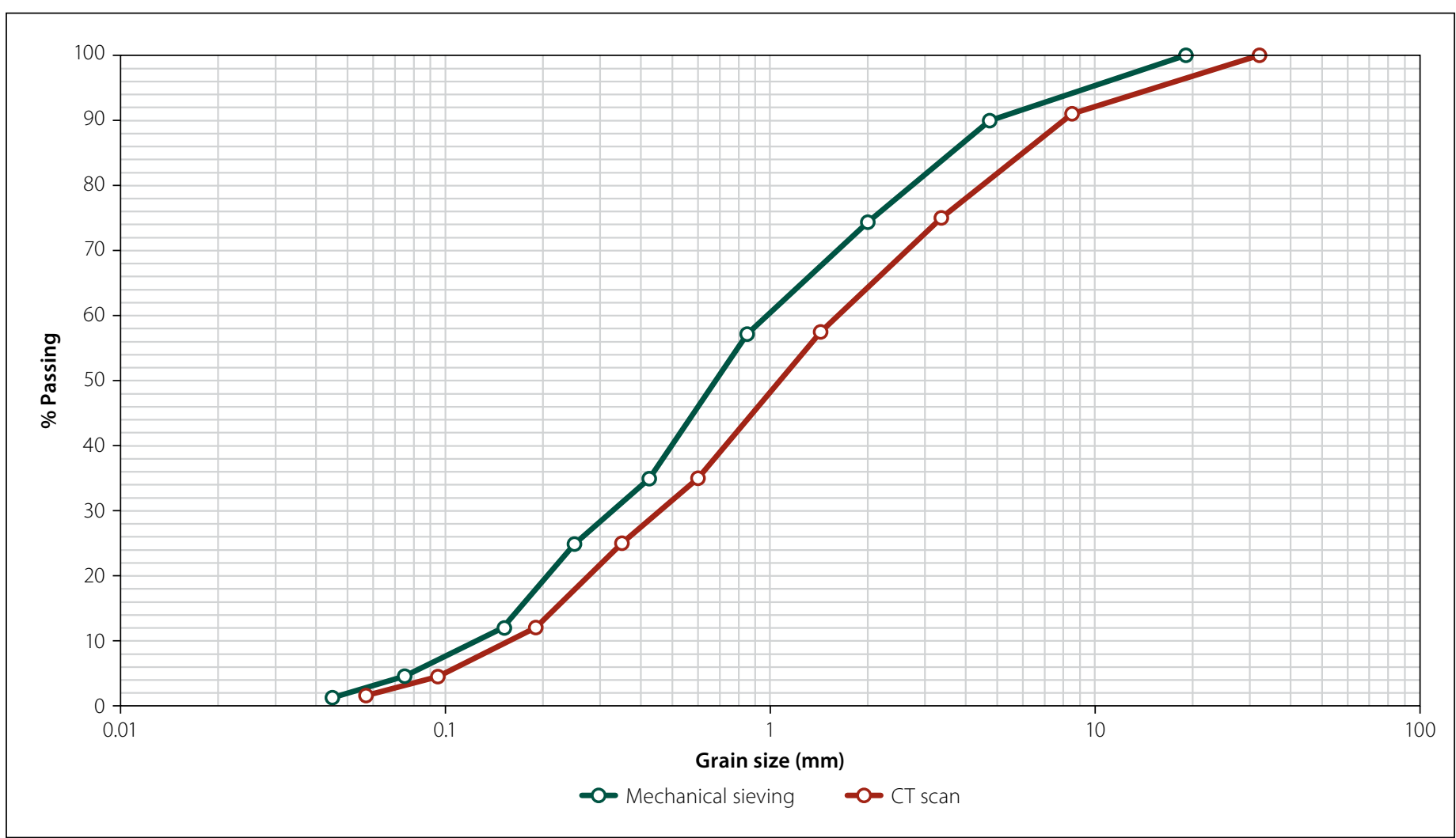

Figure 4 Comparative plot of PSD by mechanical sieving and CT-scanning (Asante 2015) 




Figure 5 Thresholding (void analysis) applied to a sliced two-dimensional image of reworked residual granite showing volumetric change in pores following collapse (Asante 2015)

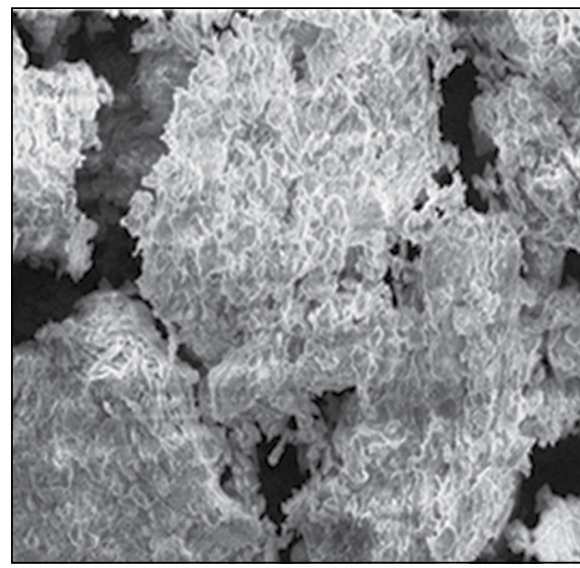

Figure 6 Microscopic view of primary quartz particles coated with illite within residual Malmesbury shale (Asante 2015)

the collapsible reworked residual granite (see Table 4).

The SEM results provided useful insights into the behaviour of collapsible soils by allowing examination of the soil microstructure. The particle morphology and mineralogy of the reworked residual granite and residual Malmesbury shale were examined and proved valuable in interpretation of the collapse potential test results. On a microscale level, the residual shale (non-collapsible) comprises rounded and sub-rounded quartz grains (larger primary mineral) coated with a thin, plate-like and flaky clay mineral, illite. These coated particles are surrounded by irregularly shaped secondary clay mineral, kaolinite, forming an interlocked structure (see typical SEM image in Figure 6). The secondary clay minerals have a preferred orientation parallel to the lamination (small-scale sequence of fine layers) which impedes the formation of a collapsible fabric. At first glance, the observed void ratios (between 0.67 and 1.45) may be misleading in predicting collapse,

Table 4 Volumetric change in pore volume during collapse of reworked residual granite and residual Malmesbury shale (Asante 2015)

\begin{tabular}{|c|c|c|c|c|c|}
\hline $\begin{array}{c}\text { Material } \\
\text { type }\end{array}$ & $\begin{array}{l}\text { Diameter } \\
\text { ( } \mu \mathrm{m})\end{array}$ & Class limit & Subclass & $\begin{array}{c}\text { Average } \\
\text { volume } \\
\text { (undisturbed } \\
\text { sample) }\left(\mathrm{mm}^{3}\right)\end{array}$ & $\begin{array}{c}\text { Average } \\
\text { volume (after } \\
\text { collapse) }\left(\mathrm{mm}^{3}\right)\end{array}$ \\
\hline \multirow{4}{*}{$\begin{array}{l}\text { Reworked } \\
\text { residual } \\
\text { granite }\end{array}$} & $>5000$ & \multirow{4}{*}{ Macropores } & Coarse & 2408.32 & 2.44 \\
\hline & $2000-5000$ & & Medium & 0.25 & 0.44 \\
\hline & $1000-2000$ & & Fine & 0.15 & 0.17 \\
\hline & $75-1000$ & & Very fine & 0.12 & 0.11 \\
\hline \multirow{4}{*}{$\begin{array}{l}\text { Residual } \\
\text { Malmesbury } \\
\text { shale }\end{array}$} & $>5000$ & \multirow{4}{*}{ Macropores } & Coarse & 9.96 & 2.50 \\
\hline & $2000-5000$ & & Medium & 0.18 & 0.24 \\
\hline & $1000-2000$ & & Fine & 0.12 & 0.13 \\
\hline & $75-1000$ & & Very fine & 0.00 & 0.12 \\
\hline
\end{tabular}


(a)

Figure 7 (a) Three-dimensional image of reworked residual granite showing void sizes, and (b) interconnected coarse voids (Asante 2015)

but these pores are unconnected (unlike the connected pores of the granitic soils), thus not lending themselves to the formation of a collapsible fabric.

The rounded and sub-rounded primary quartz minerals making up the framework of the silty sand reworked residual granite are surrounded by a fine matrix of partially leached and eroded feldspar, quartz and kaolinite and smectite clays. A porous, honeycomb-like structure is the result, leading to collapse settlement within the reworked residual granites, as observed in the collapse potential tests. A three-dimensional image of reworked residual granite from Stellenbosch, in which the network of connected coarse pores is evident, is shown in Figure 7. The soil pores, visible on the exterior surface of an undisturbed sample is shown in 7(a), whereas the connected void system is shown in 7(b). In cases where the void ratio of collapsible soils is low and potentially misleading to the engineer, examination of the soil microstructure could reveal the potential for collapse to occur. In this regard, the particle shape and orientation, and mineral composition and arrangement (no preferred orientation or lamination, forming connected pores) will prove valuable in predicting collapse.

The difference within the microstructure of the residual shale and reworked residual granite is evident when studying the images produced by SEM. The particle morphology and mineralogy of the two soil types are inherently different, leading to the formation of contrasting soil fabrics, and subsequently collapse behaviour.

\section{CONCLUSIONS}

The Cape granite soils have in the past often been overlooked by engineers and engineering geologists as a problem soil with regard to its collapse potential. The identification of collapsible Cape granite soils on the outskirts of Stellenbosch during a geotechnical investigation for farm storage structures, first drew attention to the subject. The studies carried out by post-graduate researchers from Stellenbosch University confirmed the presence of collapsible soils at the majority of sampling locations underlain by reworked residual and residual granite in the Stellenbosch, Paarl and Darling areas. 
Table 5 Summary of experimental findings for typical reworked residual granite and residual Malmesbury shale samples

\begin{tabular}{|c|}
\hline Property \\
\hline Collapse potential (\%) \\
\hline Clay content (\%) \\
\hline Void ratio \\
\hline $\begin{array}{c}\text { Change in average volume of coarse macropores } \\
\text { before and after collapse }\left(\mathrm{mm}^{3}\right)\end{array}$ \\
\hline \\
\hline 3D pore distribution \\
\hline
\end{tabular}

The collapse potential of a soil is governed by its microstructure, that is, the porosity, particle and pore size distribution, particle morphology and mineralogy. Collapsible residual granite soils often do not possess typical characteristics associated with collapse such as high porosity and low clay content; however, non-destructive methods such as CT-scanning and SEM can effectively be used to aid in identifying potentially collapsible soils by examining their microstructure. A summary of the experimental findings for typical samples of reworked residual granite and residual Malmesbury shale is given in Table 5, from which it is evident that microstructure analysis through CT-scanning and SEM can be useful in the identification of collapsible soils.

The image processing techniques employed by the researchers, resulted in the following additional conclusions:

- Collapse settlement occurs within the macropores of soils with a collapsible grain structure.

- For collapse settlement to occur, the voids must be interconnected.

\begin{tabular}{|c|}
\hline Reworked residual granite \\
\hline 9.73 (collapsible) \\
1 \\
0.98 \\
\hline
\end{tabular}

380 to 2.11

Porous structure formed by leaching of feldspar, quartz and clays producing an interconnected void system comprising coarse macropores (in red)

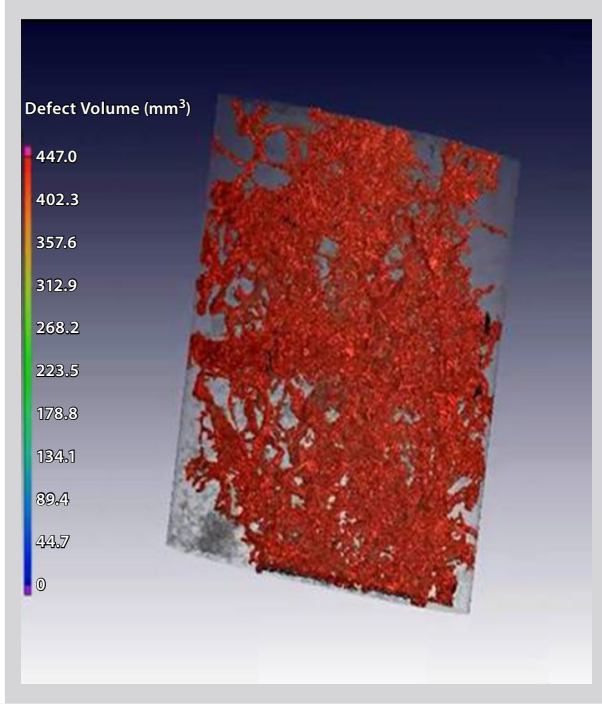

- After collapse of the soil structure, new, but smaller voids are formed.

- CT-scanning (with the appropriate image analysis technique) can be used effectively to determine the distribution of particle sizes in soils.

\section{RECOMMENDATIONS}

Further research on the topic is suggested, including an assessment of the practicality of the use of scanning electron microscopy and CT-scanning in the identification of collapsible soils.

\section{REFERENCES}

Asante, S 2015. Alternate methods to determine the microstructure of potentially collapsible soils. MEng Dissertation. University of Stellenbosch.

ASTM 2011. ASTM D2435, 2011. Standard Test Methods for One-Dimensional Consolidation Properties of Soils Using Incremental Loading. West Conshohocken, PA: ASTM International.

Brewer, R 1964. Fabric and Mineral Analysis of Soils. New York: Wiley.
Residual Malmesbury shale

0.42 (not collapsible)

52

1.3

9.96 to 2.50

Interlocked structure of coated quartz grains and laminated secondary clay minerals forming an unconnected void system comprising medium, fine and very fine macropores (in green and blue)

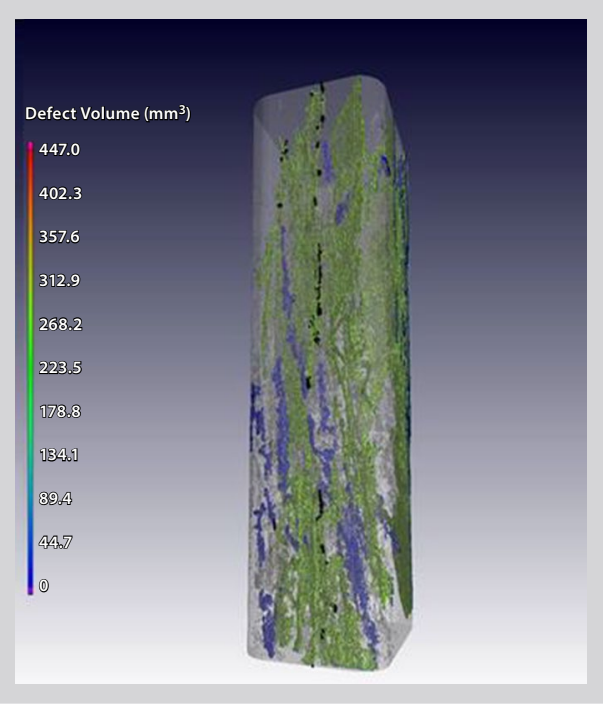

Brink, A B A 1981. Engineering Geology of Southern Africa, Vol 2. Pretoria: Building Publications.

Gildenhuys, N 2010. The occurrence and extent of collapse settlement in residual granite in the Stellenbosch area. MEng Dissertation. University of Stellenbosch.

Jennings, J E \& Knight, K A 1975. A guide to construction on or with materials exhibiting additional settlement due to collapse of grain structure. Proceedings, 6th Regional Conference for Africa on Soil Mechanics and Foundations Engineering, Durban, South Africa.

Muteb, C K 2013. Geotechnical investigation for properties of collapsible soils: A case study conducted at Darling and Paarl area. MEng Dissertation. University of Stellenbosch.

Remley, P A \& Bradford, J M 1989. Relationship of soil crust morphology to inter-rill erosion parameters. Journal of the Soil Science Society of America, 53: 1215-1221.

Schwartz, K 1985. Problem soils in South Africa State of the art: collapsible soils. The Civil Engineer in South Africa, 27(7).

TMH1 (Technical Methods for Highways) 1986. Standard Methods of Testing Road Construction Materials: Methods A1(a), A1(b), A5 and A6. Pretoria: Department of Transport. 